\title{
NOISE IN AUGER ELECTRON SPECTRA: A SIGNAL-PROCESSING VIEW
}

\section{ŠUM V AUGERJEVIH ELEKTRONSKIH SPEKTRIH - POGLED Z VIDIKA OBDELAVE SIGNALOV}

\author{
Igor Belič1 , Besnik Poniku², Monika Jenko ${ }^{1}$ \\ ${ }^{1}$ Institute of Metals and Technology, Lepi pot 11, 1000 Ljubljana, Slovenia \\ ${ }^{2}$ University of Karabuk, Faculty of Engineering, Biomedical Engineering, Kastamonu Yolu Demir Çelik Kampüsü, 78050 Kılavuzlar \\ Köyü/Karabük Merkez/Karabük, Turkey
}

Prejem rokopisa - received: 2018-10-09; sprejem za objavo - accepted for publication: 2019-01-15

doi:10.17222/mit.2018.218

\begin{abstract}
Auger electron (AE) spectroscopy is an important surface-analysis tool for conductive materials. However, the technique has a serious drawback, i.e., the absence of automated spectra analyses. The goal of our research work, therefore, was to find a way towards the automatic analysis of AE spectra, and in this paper we describe how the analysis of AE spectral noise is one of the reasons preventing automatic analyses. Knowing the properties of noise is a key to knowing the true shape of the spectral background, as well as the shape of the characteristic AE peaks. We are not interested in the properties of the noise in the sense of how and what generates it, rather we want to discover what are its manifestations and consequences from the signal-processing point of view. In the paper we give answers to several important noise-related (measured and simulated) questions: Does the noise amplitude level vary with the kinetic energy? Is the measured noise "white noise"? Is the noise temperature dependent? The answers to these questions also indicate how we can extract the AE spectral noise.

Keywords: Auger electron spectroscopy, noise, white noise, running average, Fourier transform, signal power
\end{abstract}

\begin{abstract}
Augerjeva elektronska (AE) spektroskopija je pomembna tehnika za analizo površin prevodnih materialov. Analiza posnetih spektrov ni avtomatizirana, kar predstavlja veliko slabost te analitske metode. Cilj našega raziskovalnega dela je najti pot do avtomatizacije postopkov analize AE spektrov. Prispevek opisuje, kako na analizo AE spektrov vpliva šum, ki je eden od razlogov, da analitska tehnika še ni avtomatizirana. Poznavanje lastnosti spektrom primešanega šuma je ključ do poznavanja dejanske oblike spektralnega ozadja in spektralnih vrhov. Ne zanimajo nas podrobnosti šuma v smislu njegovega nastanka, zanimajo nas njegove lastnosti, ko je spekter že izmerjen. Opazujemo ga s stališča obdelave signalov. Prispevek daje odgovore na pomembna vprašanja o šumu (merjenem in simuliranem), kot so: Ali se amplituda šuma spreminja s kinetično energijo? Ali spada izmerjen šum v kategorijo "belega šuma"? Ali je šum temperaturno odvisen? Odgovori na zastavljena vprašanja nakazujejo možnosti, kako se izogniti spektralnemu šumu.
\end{abstract}

Ključne besede: Augerjeva elektronska spektroskopija, šum, beli šum, tekoče povprečenje, Fourierov transform, moč signala

\section{INTRODUCTION}

Today, Auger electron spectroscopy (AES) represents one of the most important surface-analysis tools for samples of conductive material. AES allows the quantitative analysis of surfaces with a $0.1 \%$ sensitivity, elemental detection (excluding $\mathrm{H}$ and $\mathrm{He}$ ) with a spatial resolution of better than $10 \mathrm{~nm}$, as well as high-resolution depth profiling. AES finds applicability in the areas of microelectronics, metallurgy and the analysis of thin films. ${ }^{1}$ As a result of its high surface sensitivity ${ }^{2}$ and the ability to focus the primary electron beam to a diameter of approximately $10 \mathrm{~nm},{ }^{3}$ using Auger electron spectroscopy it is possible to characterize nanoscale surface features. ${ }^{4-9}$

A very serious drawback of AES is the absence of automated Auger electron (AE) spectra analysis. The main reason that $\mathrm{AE}$ spectra analyses have not yet been automated lies in the complexity and variability of the spectrum.

*Corresponding author e-mail igor.belic@imt.si
In our previous work we found that the shapes of measured AE spectra are, in general, composed of three principal components: the characteristic Auger electron peaks, the background, and the noise, ${ }^{10}$ as shown in Figure 1.

Our main goal was to find a way towards the automatic analysis of AE spectra. Since noise is one of the primary reasons for the absence of automatic analyses, it is necessary to understand the properties of the noise. For quite some time, the physics of the emergence of noise has been known and well documented. ${ }^{11}$ It is known, for example, that the AE spectra noise is a Poisson noise (Shot noise). However, in our work we are not interested in understanding the principles of how the noise is being produced. Our view is turned in a completely different direction. Once the $\mathrm{AE}$ spectrum is recorded, we take it as the signal that is to be analysed with a very clear focus in mind being how to remove it from the signal.

The present paper describes an analysis of the properties of AE spectral noise from the signal-processing point of view. We are directly interested in what are the 


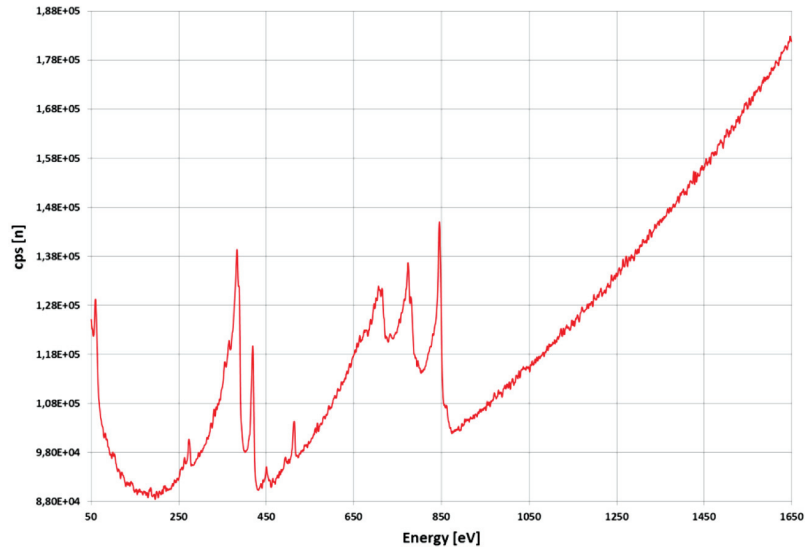

Figure 1: AE spectrum from NiTi shape-memory alloy. AE spectra are, in general, composed of three principal components: the characteristic Auger electron peaks, the background, and the noise

manifestations and consequences of noise that is added to the spectra. In this regard several questions were addressed:

1. Does the amplitude of the noise vary with the kinetic energy of the AE spectra?

2. What is the Fourier spectral composition of the noise - does the measured noise fall into the category of "white noise"?

3. Is the noise temperature dependent? (In materials science adsorption and segregation experiments are often conducted, ${ }^{12-19}$ which may involve either heating the sample in situ or fracturing the previously aged sample while cooling it in situ by indirect contact with liquid nitrogen.)

In order to develop reasonably reliable software for the analysis of AE spectra, a large number of spectra are required. Furthermore, to be able to assess the quality of the developed analysis software, the exact composition of the analysed spectra must be a-priori known. This condition can only be met with simulation software that generates virtual AE spectra. Then, only with a thorough knowledge of the behaviour of the analysis software can it be safely used on real AE spectra.

Since a simulator of AE spectra has already been developed and described in our previous work, ${ }^{20,21}$ and since the generation of the simulated spectra takes considerably less time than measuring spectra with the instrument, the answers to the following simulationrelated questions were also of great interest:

$\mathrm{S} 1 \mathrm{Can}$ the noise produced by the AE spectra simulator be compared to the measured noise?

S2 What are the differences between the measured and simulated noise?

S3 Can the simulated noise adequately represent the measured noise or should the AE spectra simulator be appropriately tuned in order to give a better representation of the measured noise?

To answer these questions, $247 \mathrm{AE}$ spectra from spring-steel samples and NiTi shape-memory alloy samples were recorded and analysed. To allow a direct comparison of the results, the same number of $\mathrm{AE}$ spectra was simulated and analysed.

\section{METHODOLOGY}

In order to study the properties of the AE spectra, including the noise, several data-analysis tools were used. Our starting hypothesis was that the noise is close to so-called white noise. Therefore, a set of tools was selected that enables us to test the properties of the noise. First, the noise must be separated from the background. For this purpose a running-average algorithm was used. Since, by definition, the white noise must have a zero mean value, the criterion of optimality for the runningaverage algorithm is set to produce the extracted noise with mean values as close as possible to zero. Once the noise is extracted, a discrete Fourier transformation is used to calculate the complex-valued composition of the noise in the frequency domain. The Fourier transform of the noise is used to calculate the noise power spectral density needed to further prove the properties of the white noise. Finally, the auto-correlation of the noise was calculated, proving the randomness of the noise. What follows is a very brief summary of the tools that were used.

\subsection{White noise}

The term white noise refers to a statistical description of the signals and the signal sources. White noise is a random signal with a flat (constant) power spectral density. In its discrete form it is a data sequence containing equal power within any frequency band of a fixed width. The term is also used to describe a signal whose samples are regarded as a sequence of uncorrelated random variables with zero mean and finite variance..$^{22,23}$ White noise is a general category that can be further divided into somewhat narrower classes having a flat, Gaussian, Poisson (Shot) or any other distribution of data samples (e.g., representing amplitudes).

\subsection{Running average}

The running-average process is used to separate the AE spectral noise from the background. It is a method where a series of consequent averages of data subsets (averaging windows) is calculated. It is a data-filtering method referred to as a finite-impulse response filter. ${ }^{24}$

We begin with a function $y=f(x)$ where both $x$ and $y$ are a discrete set of data points and the function is defined within the closed interval $\left[x_{\min }, x_{\max }\right]$. The width of the window is denoted by $w$ (an odd integer!). In addition, the value $\mathrm{w}_{12}$ is defined, representing the integer quotient for the division of $w$ by 2 . Therefore, the definition

$$
w=2\left(w_{12}\right)+1
$$

holds true. 
The running-average function is defined as

$$
R(x)=\frac{1}{w} \sum_{x_{\mathrm{s}}=x-w_{12}}^{x+w_{12}} f\left(x_{\mathrm{s}}\right)
$$

The function $R(x)$ is defined on the closed interval $\left[x_{\min }+w_{12}, x_{\max }-w_{12}\right]$, which is the subset of the interval on which the original data reside.

The width $w$ (number of data points forming the window) of the averaging window controls the smoothness of the gathered running-average function. The wider the window, the smoother the running-average function becomes. Since the running average is used to filter out the fluctuations caused by the noise, it would be appropriate to widen the window as much as possible. On the other hand, the process also affects the original function that is already distorted by the noise. The selection of the averaging window's width is therefore a trade-off situation between the noise suppression and the degradation of the original function. For each problem the width of the optimal averaging window should be determined, where the optimality criterion is to produce extracted noise with a mean value closest to zero.

\subsection{Fourier transformation for non-periodic functions}

A physical process can be described either in the time domain using the values of some quantity $f$ as a function of time $f(t)$ or else in the frequency domain where the process is specified by giving its amplitude $F$ as a function of the frequency $\omega$, i.e., $F(\omega)$, with $-\infty<\omega<\infty$. It is useful to think of $f(t)$ and $F(\omega)$ as being two different representations of the same function.

It is important to note that originally the principle of a Fourier analysis operates in the time and frequency domains. ${ }^{25}$ This is, however, just a matter of interpretation. In many cases a Fourier analysis is used for image processing, where the time and frequency domains are replaced by the length and spatial frequency. In the case of AES the $E$ (energy) and $1 / E$ spaces are observed.

The definitive Fourier-transform equations are:

$$
\begin{aligned}
& F(w)=\int_{-\infty}^{\infty} f(t) e^{i \omega t} \mathrm{~d} t \\
& f(t)=\frac{1}{2 \pi} \int_{-\infty}^{\infty} F(w) e^{i \omega t} \mathrm{~d} \omega
\end{aligned}
$$

\subsubsection{Discrete Fourier transform}

When the Fourier transform of a function is estimated from a finite number of samples, the discrete Fourier transform replaces the continuous form ${ }^{25}$. In such cases we have $N$ equidistant $\left(\mathrm{D}=t_{\mathrm{k}+1}-t_{\mathrm{k}}\right.$ ) sampled values

$$
f_{\mathrm{k}} \equiv f\left(t_{\mathrm{k}}\right), \quad t_{\mathrm{k}} \equiv k \Delta, \quad k=0,1,2, \ldots, N-1
$$

With $N$ numbers of input, it is possible to produce no more than $N$ independent numbers of output. Instead of estimating the Fourier transform $F(\omega)$ for all the values of $\omega$ in the range $-\omega_{\mathrm{C}}$ to $\omega_{\mathrm{C}}$ we only have estimates for discrete values

$$
f_{\mathrm{n}} \equiv \frac{n}{N \Delta}, n=-\frac{N}{2}, \ldots, \frac{N}{2}
$$

The discrete Fourier transform replaces the integral by the discrete sum

$$
\begin{aligned}
& F\left(w_{\mathrm{n}}\right)=\int_{-\infty}^{\infty} f(t) e^{i \omega_{\mathrm{n}} t} \mathrm{~d} t \approx \\
& \approx \sum_{k=0}^{N-1} f_{\mathrm{k}} e^{i \omega_{\mathrm{n}} t_{\mathrm{k}}} \Delta=\Delta \sum_{k=0}^{N-1} f_{\mathrm{k}} e^{\frac{i k n}{N}}
\end{aligned}
$$

The inverse discrete Fourier transform is therefore

$$
f(k)=\frac{1}{2 \pi N} \sum_{k=0}^{N-1} F_{\mathrm{n}} e^{\frac{i k n}{N}}
$$

\subsection{Power spectral density}

Parseval's theorem

$$
P \equiv \int_{-\infty}^{\infty}|f(t)|^{2} \mathrm{~d} t=\int_{-\infty}^{\infty}|F(\omega)|^{2} \mathrm{~d} \omega
$$

establishes the total power $P$ in the time and frequency domains. ${ }^{25}$ The total power $P$ is the same, whether it is calculated in the time domain or in the frequency domain. Usually, it is important to know the amount of power contained in the frequency interval between $\omega$ and $\omega+d \omega$. The function describing such power intervals is referred to as the power spectral density.

Although the complex Fourier spectrum spans the $-\infty<\omega<\infty$ space, when dealing with power, it is convenient to operate on the one-sided interval $0 \leq \omega<\infty$ only. In such cases the one-sided power spectral density of the function $f$ is defined as

$$
P_{\mathrm{f}}(\omega) \equiv|F(\omega)|^{2}+|F(-\omega)|^{2} \quad 0 \leq \omega<\infty
$$

When the function $f(t)$ is real (as is true in our case), then both terms are equal, resulting in

$$
P_{\mathrm{f}}(\omega) \equiv 2|F(\omega)|^{2}
$$

The concept of the power spectral density is important for an assessment of the noise's spectral properties.

\subsection{Correlation function}

A correlation function is a measure of the similarity for two data sequences. It is commonly used to search a data sequence for a known feature. ${ }^{16}$ The correlation provides a useful indicator of similarity as a function of a lag in time, space, or any other quantity.

The cross-correlation $C(f, g)$ of two real functions $f(t)$ and $g(t)$ is defined by:

$$
C(f, g)=\int_{-\infty}^{\infty} f(t+\tau) g(t) \mathrm{d} t
$$

The correlation is a function of the time lag $\tau$. For real discrete functions, the cross-correlation is defined as: 


$$
C(f, g)=\sum_{m=-\infty}^{\infty} f(m+n) g(m)
$$

The special case of the correlation is an auto-correlation, which is the cross-correlation of a data sequence with itself.

\section{EXPERIMENTAL PART}

\subsection{Measurements}

Two types of materials were used in this investigation. In total, $247 \mathrm{AE}$ spectra from both types of samples were recorded.

One set of samples consisted of spring steel provided by the Štore Steel Company, which was used for measuring $\mathrm{AE}$ spectra while analysing for non-metallic inclusions present in these samples. Two specimens were taken from the bulk material, both with dimensions of $(10 \times 10 \times 4) \mathrm{mm}$. First, the samples were cut from the bulk material by abrasive wet cutting. Afterwards, the samples were subjected to plane grinding and then fine grinding. Then, they were polished, first with diamond polishing and then oxide polishing. Oxide polishing produces a finer surface, which is necessary for Auger electron spectroscopy. Finally, the samples were cleaned with ultrasound to remove any impurities that may have been introduced onto the surface during the preparation.

The composition of these spring-steel samples (excluding iron) is given in Table 1. The primary electron beam used for probing these samples was of $10-\mathrm{keV}$ energy, 10-nA intensity, and 10-nm beam diameter.

Table 1: The elemental composition of spring-steel samples used in obtaining the measured AE spectra

\begin{tabular}{|c|c|}
\hline Elements & Atomic $\%$ \\
\hline $\mathrm{C}$ & 0.47 \\
\hline $\mathrm{Si}$ & 0.15 \\
\hline $\mathrm{Mn}$ & 0.7 \\
\hline $\mathrm{P}$ & 0.035 \\
\hline $\mathrm{S}$ & 0.035 \\
\hline $\mathrm{Cr}$ & 0.9 \\
\hline $\mathrm{V}$ & 0.1 \\
\hline
\end{tabular}

The other set of samples consisted of NiTi shape-memory alloy. This material was a commercial Ni $50.74 \%$ $(x / \%)$, Ti alloy with the composition according to ASTM 2063-05. It was in sheet form with the following dimensions: $0.5 \pm 0.05 \mathrm{~mm}$ thick, $100 \pm 1.5 \mathrm{~mm}$ wide, and $300 \pm 3 \mathrm{~mm}$ long. It was produced by Baoji Seabird Metal Material Co., Ltd., in the flat annealed condition. The sheet was cut into flat samples of $10 \mathrm{~mm}$ in diameter using a water jet. The samples were prepared according to Struers instructions with $\mathrm{SiC}$ \#paper 220, rough polished by MD-largo, 9- $\mu \mathrm{m}$ diamond paste and oxide polished using Struers MD-Chem, OPS (90 mL OPS + $10 \mathrm{~mL} \mathrm{H}_{2} \mathrm{O}_{2}$ ); with a polishing time of $10 \mathrm{~min}$.

To address question no. 3, a sample of NiTi alloy was mounted into the experimental device developed at the institute for studying the equilibrium surface segregation of residual impurities and alloying elements in situ in an ultra-high-vacuum environment in the analysing chamber of a Microlab 310-F spectrometer. The linear heating method (LHM) in the temperature range from $200^{\circ} \mathrm{C}$ to $800{ }^{\circ} \mathrm{C}$ was applied, and the temperature was measured using a K-type thermocouple.

Initially, the sample was heated to $200{ }^{\circ} \mathrm{C}$ and the surface was cleaned by argon-ion sputtering to remove the adsorbed impurities. The sample was kept at this temperature for $30 \mathrm{~min}$ and then AES measurements were made. We continued this procedure up to $800{ }^{\circ} \mathrm{C}$ where the temperature was linearly increased by $30{ }^{\circ} \mathrm{C}$ every $30 \mathrm{~min}$ and the AES analyses were made. The primary beam energy was $10 \mathrm{keV}$ at a current of $10 \mathrm{nA}$.

The Microlab 310-F that was used to record the AE spectra from all the samples is equipped with a Schottky field-emission source that provides a stable electron beam in the accelerating voltage range from $0.5 \mathrm{keV}$ to $25 \mathrm{keV}$. The electron analyser is of the double-focusing spherical-sector type with an electrostatic input lens and can provide an energy resolution between $0.02 \%$ and $2 \%$. The spectrometer has five sequential channeltrons (electron detectors), each of which detects $2.5 \%$ of the pass energy. Spectra are mostly acquired with a constant retard ratio (CRR) of 4 , which provides an energy resolution that is $0.5 \%$ of the pass energy.

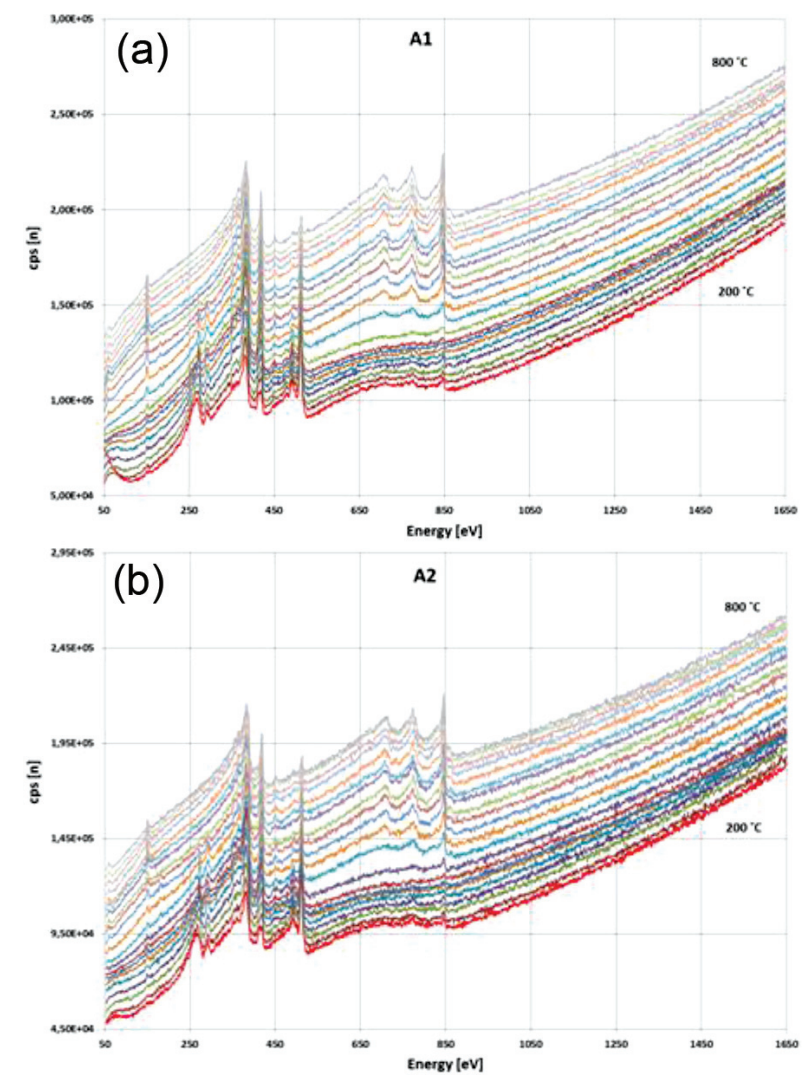

Figure 2: Auger electron spectra measured at points A1 and A2 on a NiTi shape-memory alloy sample while the temperature was increased from 200 to $800{ }^{\circ} \mathrm{C}$ in $30{ }^{\circ} \mathrm{C}$ increments 
The AES spectra were acquired using Avantage $v$ 3.41 data acquisition. The data-processing software was supplied by Thermo Scientific. CasaXPS software was used for the detailed data processing.

The measurements for investigating the effect of the sample temperature on the noise content in the $\mathrm{AE}$ spectra were conducted at two locations on the NiTi sample. The number of spectra measured at each point was 21 , with the first spectra being measured at $200{ }^{\circ} \mathrm{C}$, and with the last ones being measured at $800{ }^{\circ} \mathrm{C}$. The overlaid and offset spectra from this set of measurements are presented in Figure 2.

\subsection{Simulation}

The AES simulator ${ }^{12}$ was used to generate data sets containing only noise within the amplitude limits as detected in the measured spectra. This step only equates the maximum amplitudes of the simulated noise to that of the measured noise, but the pseudo-randomness of the generator, which is its inherent property, needs to be investigated as the findings are related to the measured noise. To allow a direct comparison with the measured spectra the number of generated noise sequences was 247 . Since the files contain only generated noise, without the background, noise-extraction procedures were not required.

\section{RESULTS AND DISCUSSION}

To investigate the AE spectral noise it is first necessary to identify the regions of the AE spectra that are not populated by spectral peaks. If possible, these regions should be large enough to allow an analysis and a comparison between the different AE spectra. The selection of the sample material was such that the high-energy portions of the measured spectra contained no spectral peaks (Figure 3). In the case of the spectra recorded from the NiTi samples, the portion of the spectrum from $875 \mathrm{eV}$ to $1650 \mathrm{eV}$ satisfied this condition, whereas in the case of the spectra recorded from the

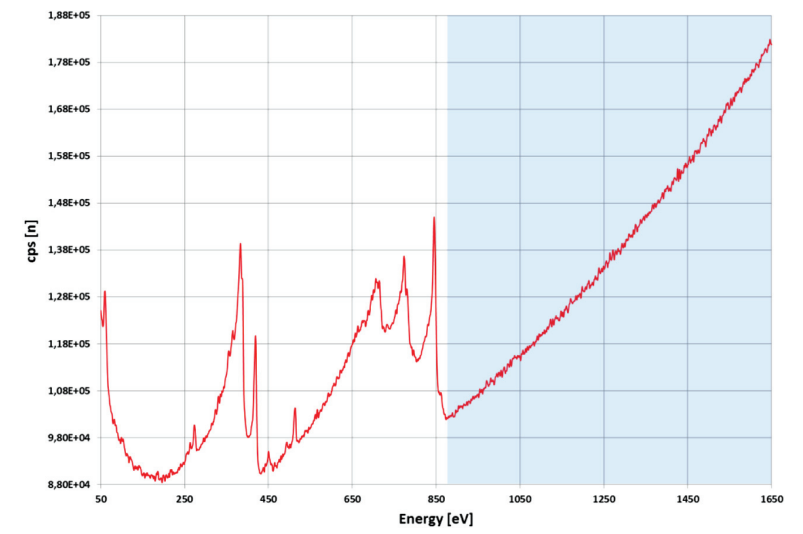

Figure 3: Extraction of the portion of the spectra containing no characteristic peaks (NiTi shape-memory alloy)

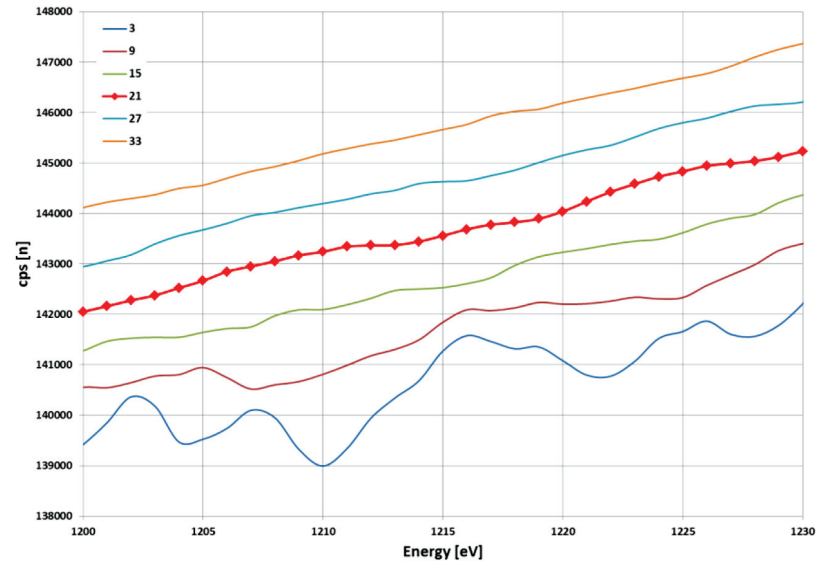

Figure 4: Effect of the choice of window width on the resulting background

spring-steel samples the portion of the spectrum from $999 \mathrm{eV}$ to $1630 \mathrm{eV}$ was chosen.

To separate the noise from the background, the optimal window width running-average algorithm was used (Equations 1, 2). It must be mentioned that the result of the running-average process is highly dependent on the choice of the used window width (Figure 4). If a small window width is used, the background resulting from the running average follows the noise more closely, as indicated by the two lowest lines in Figure 4, where the running average was obtained by using window widths of 3 and 9. The background is due to the small averaging window width, which is still quite populated by noise and the level of the extracted noise is far too low. Using wider window widths the background becomes smoother and the level of the extracted noise becomes higher. The red line in Figure 4 indicates the running average (background) obtained by using a window width of 21 . It was noted that when using window widths greater than 21 the RMS (Root Mean Square) of the extracted noise does not become much higher (Figure 5). In the experiments where the optimal window width was searched for, the minimal window width was limited to 21 points.

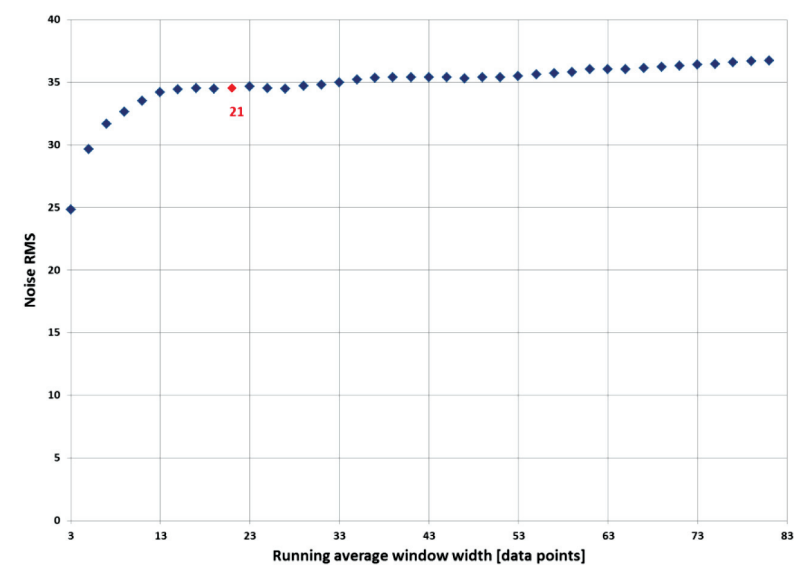

Figure 5: Level of extracted noise expressed in RMS (Root Mean Square) as a function of the window width used for averaging 


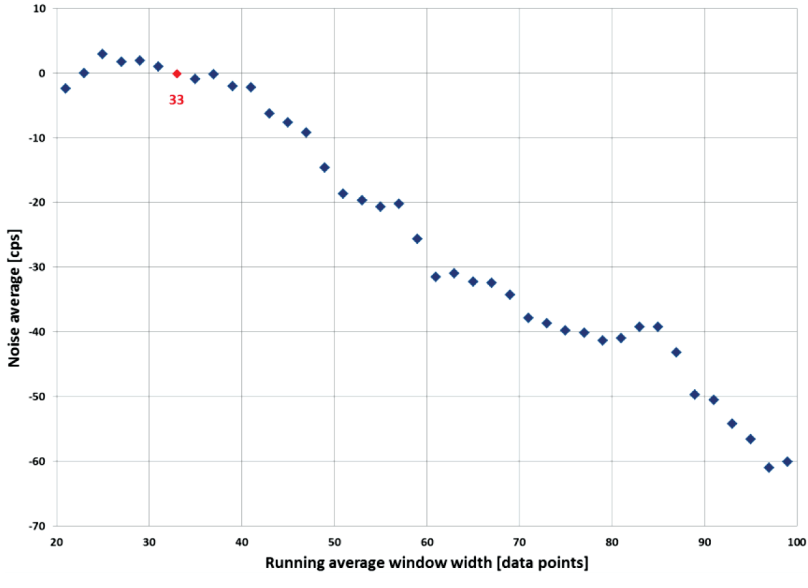

Figure 6: Finding the optimal window width for the running average

Figure 5 shows a plot of the level of noise extracted through the running-average process. The level of noise in this figure is expressed by the noise RMS as a function of the window width used for the averaging.

It is evident from Figure 5 that from a certain point on, a further increase of the window width does not improve the noise extraction very much. From the experimental work with a number of AE spectra, the conclusion was reached that the smallest window width used for our study should be larger than 21 data points.

The complete process for separating the background from the noise at the high-energy portion of the AE spectra involves several steps. For each recorded spectrum the optimal averaging window width is determined. The optimal window width should ensure that the extracted noise has a zero mean value, or that it is as close as possible to it. Such a process of finding the optimal window width for performing the running average for one data set is shown in Figure 6.

In this case a window width of 33 data points was used, since from observing Figure 6 it is the one that produces an extracted noise with an average closest to zero. For the same file the resulting background is shown in Figure 7, and the extracted noise is shown in Figure 8.

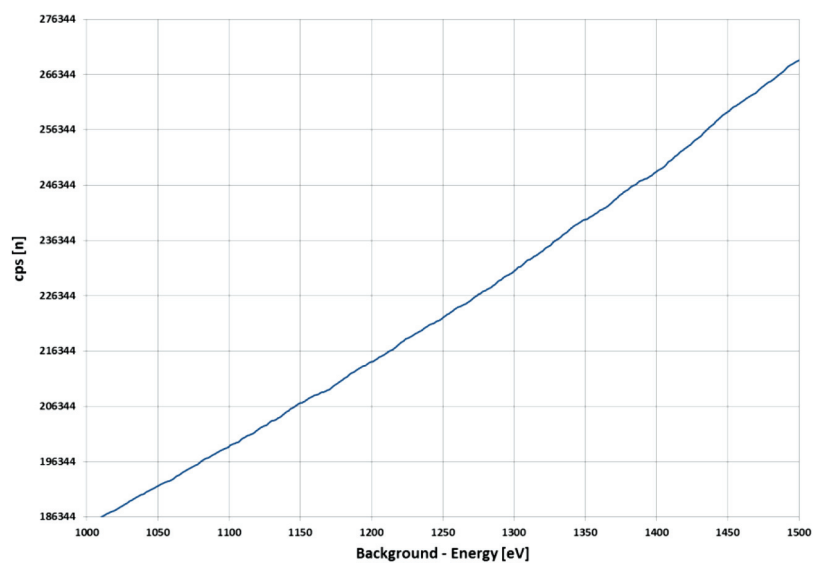

Figure 7: Extracted background obtained through the running average using a window width of 33

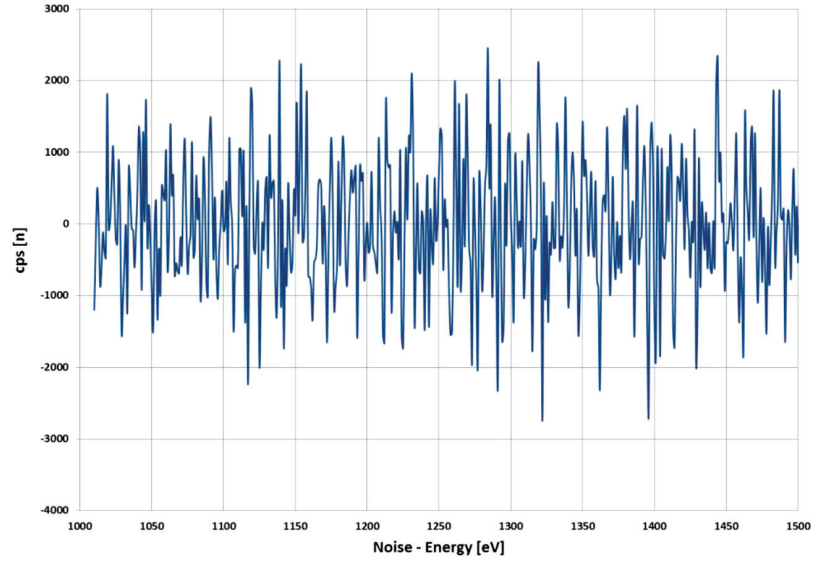

Figure 8: Extracted noise using a window width of 33 points for performing the running average

After extracting the noise, the Fourier analysis follows, where both the real and imaginary parts are calculated (Equations 3,4), as shown in Figure 9.

From both parts of the complex Fourier spectrum the single-sided power spectrum is calculated, as illustrated in Figure 10.

Finally, from the normalized power spectrum, the power spectral density was calculated (Equations 5, 6), as shown in Figure 11.

The normalization was performed since only the shape of the power spectral density is of interest here. The normalization process also enables a comparison between the power spectral densities of spectral portions with other files. As can be seen in Figure 11, the shape of the power spectral density resembles that of white noise..$^{22,23}$

The same steps were performed for the rest of the measured AE spectra. In order to get statistically relevant results regarding the properties of the noise, the following steps were carried out:

a) For all the files, the noise was normalized according to the absolute maximum amplitude, and then the cumulative noise was obtained by adding the extracted and normalized noise at each data point for all 247 cases;

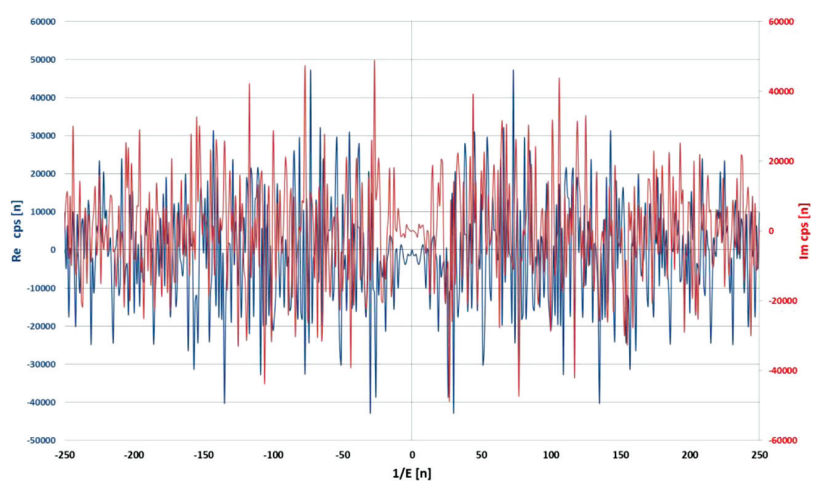

Figure 9: Real (blue) and imaginary (red) parts obtained by performing a Fourier transform on the extracted noise 


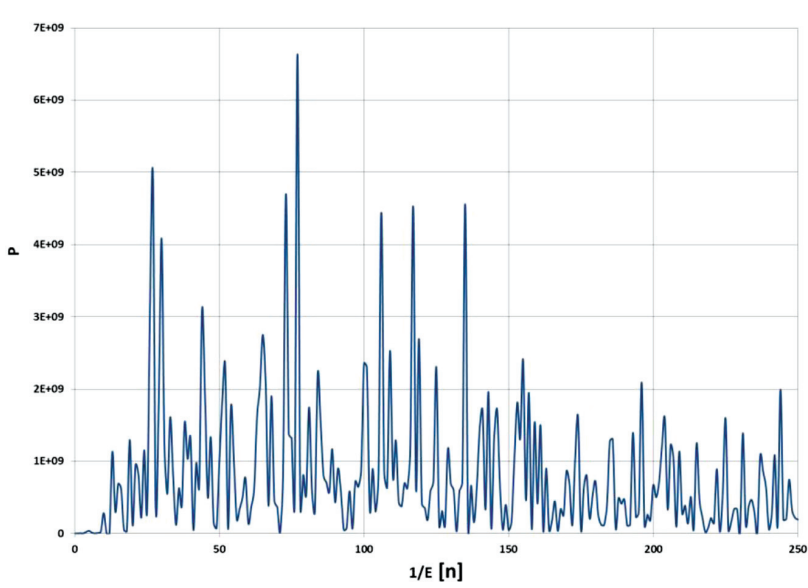

Figure 10: Single-sided power spectrum of the extracted noise

b) The accumulated noise was assessed regarding the amplitude vs. energy relationship;

c) The absolute amplitude distribution was calculated;

d) The Fourier transform of the accumulated noise was calculated;

e) The power spectral density of the noise was calculated.

The result of the noise-accumulation process is presented in Figure 12.

From Figure 12 we can conclude that there is no detectable pattern in the accumulated noise. The shape of the accumulated noise is still very much the same as it was for each individual sample. The noise amplitude does not get statistically higher, or lower, while moving over the energy scale. Had it been otherwise, due to the accumulation process, the effect would have been immediately detected.

The plot of the noise power spectral density (Figure 13), calculated from the Fourier transform of the accumulated noise, shows that its properties are similar to the one from a single spectrum, and it also reveals properties that are close to the concept of white noise.

This presumption of white noise is further supported by performing a plot of the autocorrelation function

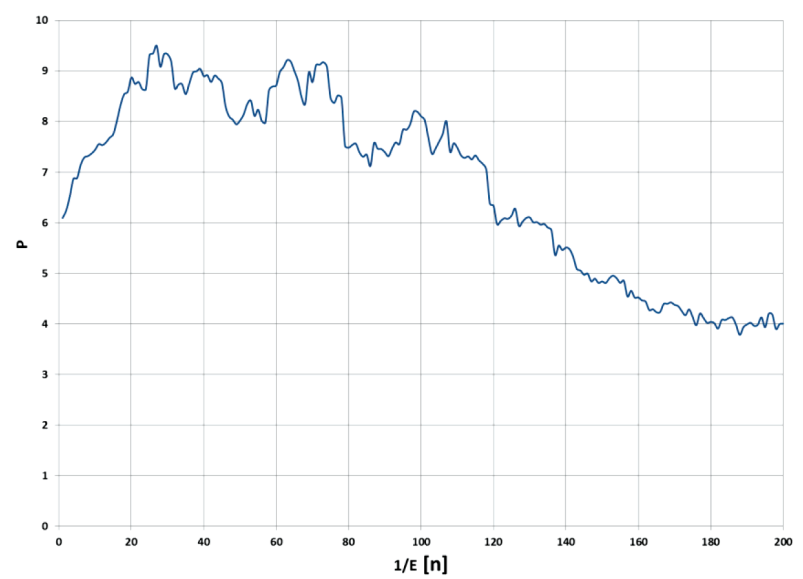

Figure 11: Power spectral density of the extracted noise

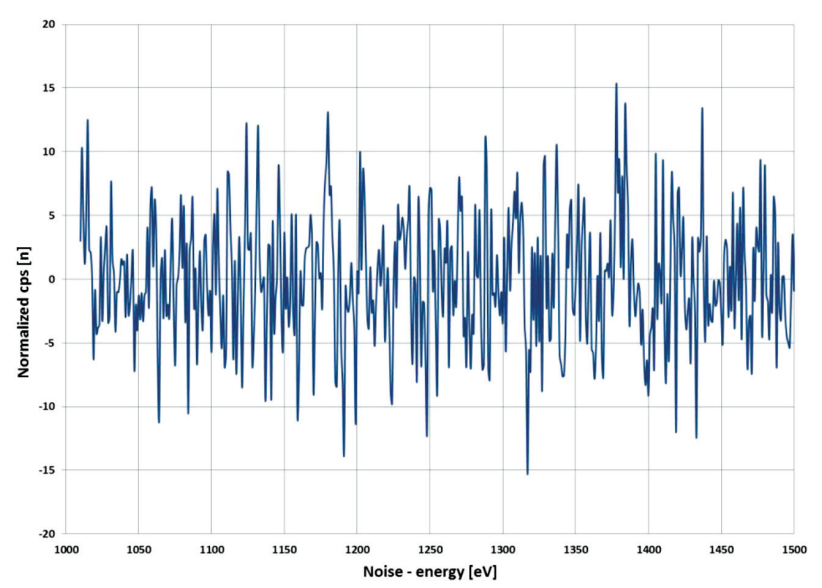

Figure 12: Accumulated noise from the extracted and normalized noises of the 247 data sets

(Equations 7,8) of the accumulated noise in which there is a strong spike around the zero shift, whereas in the rest of the shift axis there are no significant peaks. This form of the plot of the autocorrelation function is a typical property of white noise, i.e., there are no periodically similar elements detected in the noise. The plot of the autocorrelation function is presented in Figure 14.

To answer questions $\mathrm{S} 1-\mathrm{S} 3$ posed in the introductory part, the same number (247) of AE spectra were simulated in order to allow a direct comparison with the results obtained from the measured $\mathrm{AE}$ spectra.

After generating the required number of files containing random noise, its analysis followed. Since the files contain only generated noise without the background, all the steps that were carried out previously in the measured spectra were carried out in this case as well, with the exception of the separation of the background and the noise, which was not necessary. Figure 15 shows the accumulated noise from 247 simulated data sets.

Following on from the Fourier transform and the single-sided power spectrum of the noise in Figure 16, the power spectral density of the accumulated noise from the simulated data sets is calculated.

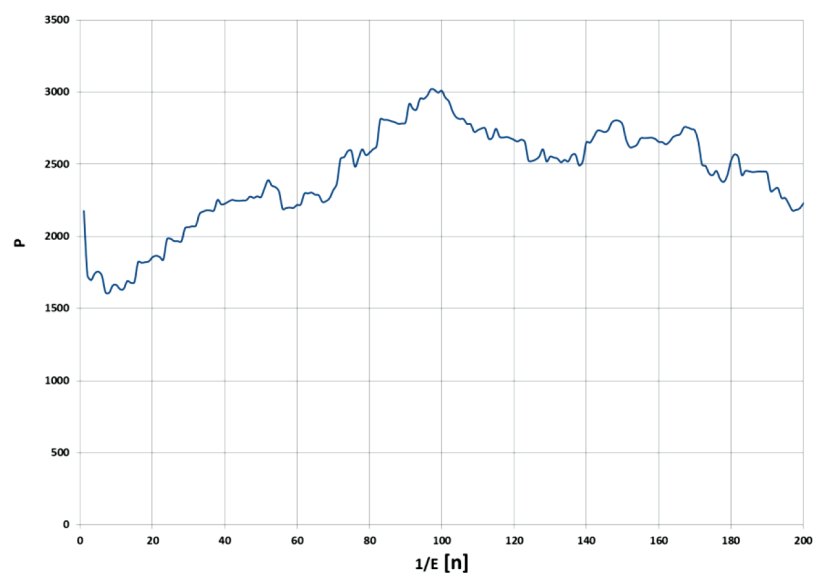

Figure 13: Power spectral density of the accumulated noise 


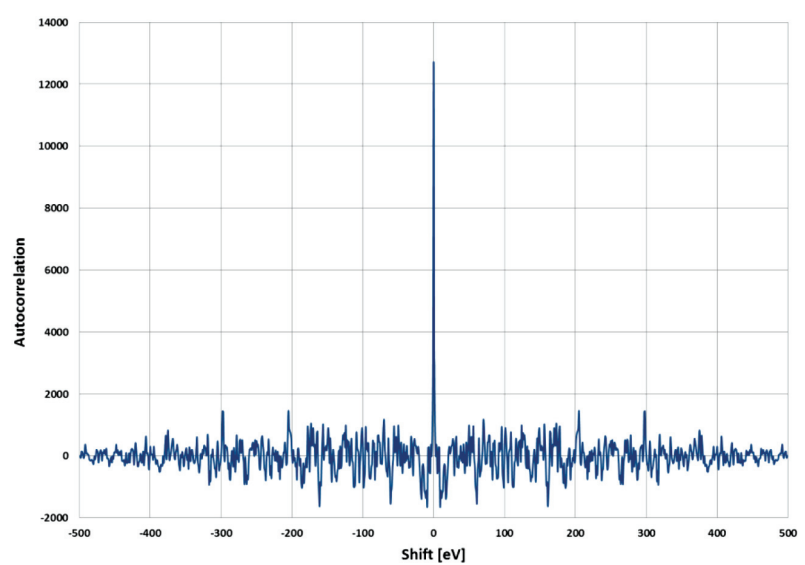

Figure 14: Plot of the autocorrelation function of the accumulated noise

Figure 16 shows that the simulated noise displays the characteristics of white noise as well. If we take a look at the amplitude distribution of the measured noise and the simulated noise (Figure 17), it is evident that the simulated noise exhibits a more uniform amplitude distribution. This results in a power spectral density for the generated noise, as displayed in Figure 16, which is closer to the ideal white noise than the measured one.

\subsection{Noise and temperature dependence}

The data of the AE spectra recorded for investigating the effect of the sample temperature on the noise content were additionally treated. Initially, the spectra were transformed from the $E \times N(E)$ vs. $K E$ (Energy $\times$ Number of electrons as a function of energy vs. the Kinetic energy of the electrons) to the $N(E)$ vs. $K E$ (Number of electrons as a function of energy vs. the Kinetic energy of the electrons) form of representation by dividing the $C P S$ (Counts per second) values by the $K E$ values at each data point (in our case the energy step size was $1 \mathrm{eV}$ ). Figure 18 represents such a case for one spectrum.

This was performed based on the assumption that along with the magnification of the signal for better peak

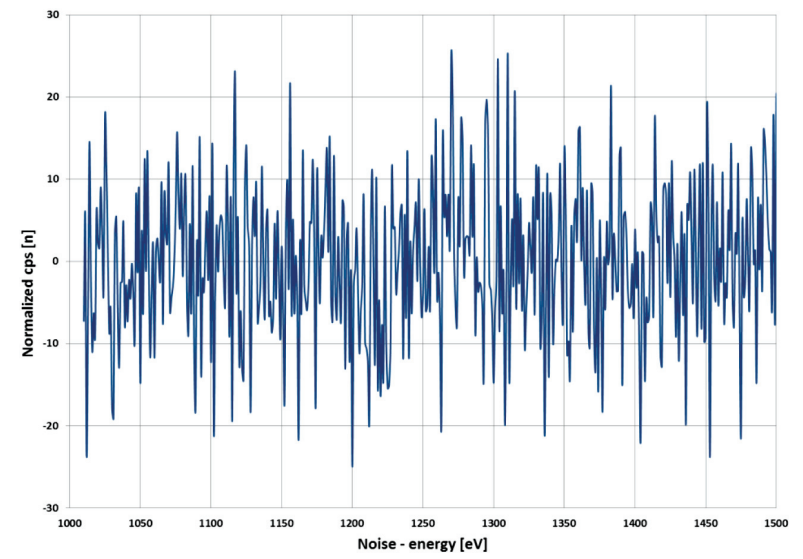

Figure 15: Accumulated noise from the normalized noises of the 247 simulated data sets

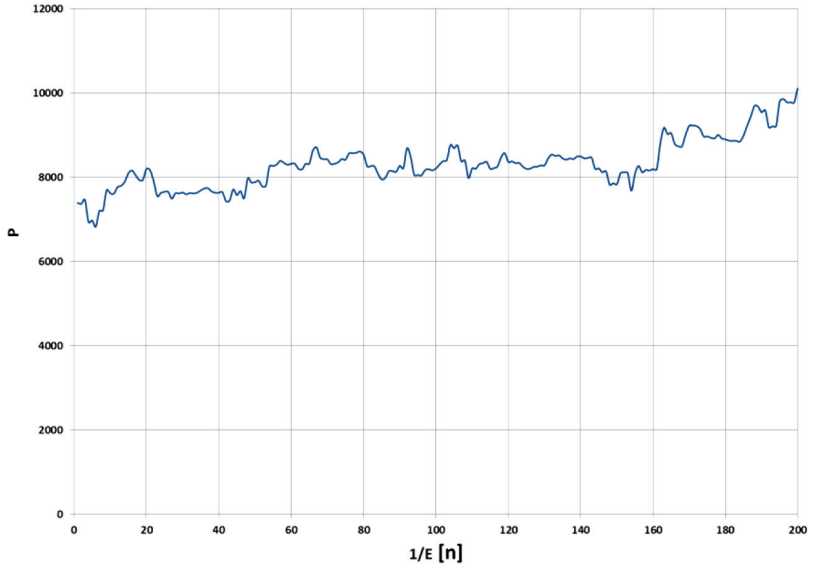

Figure 16: Power spectral density of the accumulated noise from the simulated data sets

visibility, by multiplying the $N(E)$ signal by the $K E$ values the noise also becomes magnified. On the other hand, when moving from the $E^{*} N(E)$ vs. $K E$ to the $N(E)$ vs. $K E$ form of representation, the interval of interest $(875-1650 \mathrm{eV})$ approaches a horizontal line, as in Figure 18 (red). Not having any exact function to calculate the real signal and relate the noise to, through this form of representation it was possible to conduct the averaging using a wider window.

The procedure was continued by finding the average of the transformed signal by applying a moving average for which a window of 21 data points was arbitrarily chosen. Then the standard deviation from this averaged signal was calculated for all of the 42 spectra (21 at point A1 and 21 at point A2 on the sample), since the standard deviation from the average was chosen to be used as a representation of the noise content. The same procedure was applied in all the spectra that were taken into consideration in this study, and since the objective is just a comparison of the noise levels of the spectra measured at one point at different temperatures, we believe that this form of approaching the problem is valid. Figure 19

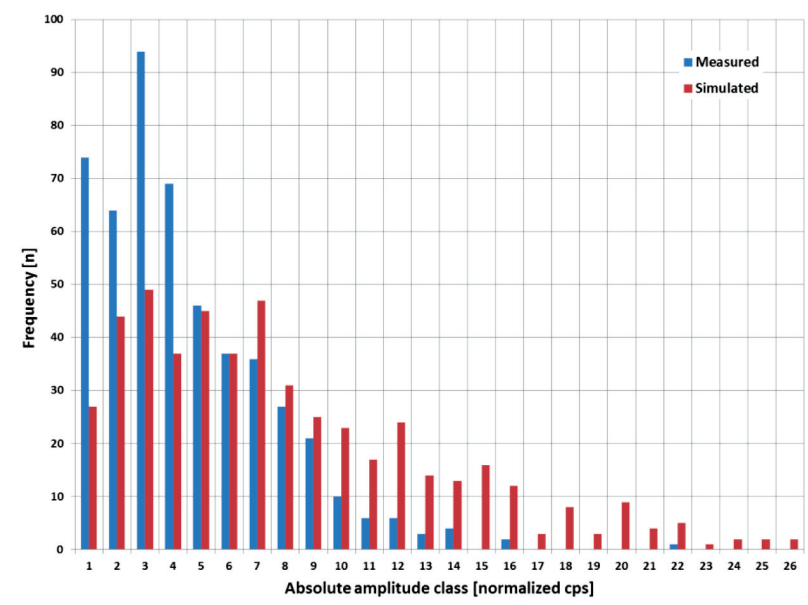

Figure 17: Amplitude distribution of the measured noise (blue) and the simulated noise (red) 


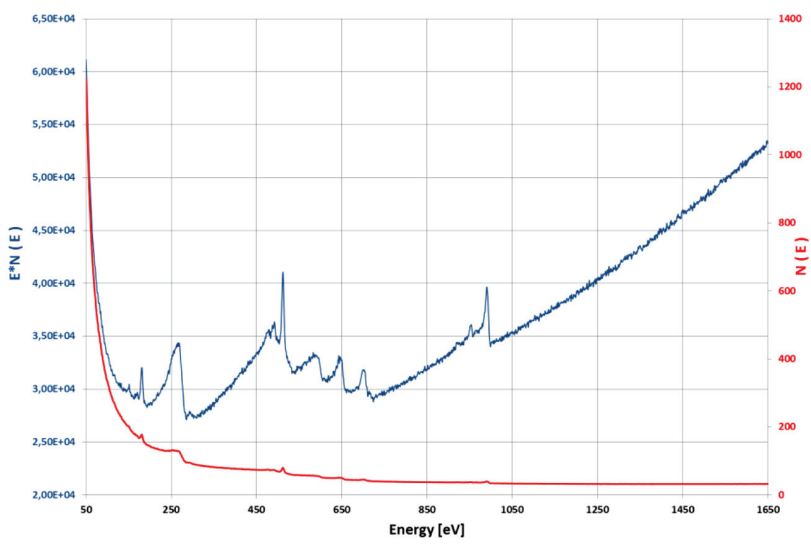

Figure 18: Auger electron spectrum of NiTi alloy represented in $\mathrm{E}^{*} \mathrm{~N}$ (E) vs. kinetic energy (blue) and N (E)(red) vs. kinetic energy

presents the noise given as the peak-to-peak difference and as a standard deviation for the 21 spectra measured at point $\mathrm{A} 1$ and the 21 spectra measured at point $\mathrm{A} 2$ in the interval $200-800{ }^{\circ} \mathrm{C}$.

As can be seen from Figure 19, the values of the standard deviation for the set of spectra measured at one point on the sample are relatively constant, indicating that the noise level in the AE spectra stayed almost the same, even though they were measured in a temperature interval $200-800{ }^{\circ} \mathrm{C}$ in steps of $30{ }^{\circ} \mathrm{C}$.

\section{CONCLUSIONS}

The aim of this study was not to investigate in detail all the contributions to the noise in the AE spectra and to describe the theory behind each mechanism. Rather, it was to better understand some of the properties of the noise in the AE spectra that would be useful to us for preparing the AE spectra for automated analyses.

Based on the results presented in this paper the questions posed in the introduction can be answered as follows:

1. Does the noise amplitude level vary with the kinetic energy of the AE spectra? When observing the direct form of the AE spectra the noise amplitude level does not vary with the AE kinetic energy (Figure 12). This is important because the same conclusions about the noise (reached by analysing the higher-energy portion of the spectra without spectral peaks) can be safely extrapolated to other spectra regions.

2. What is the Fourier spectral constitution of noise does the measured noise come into the category of "white noise"? The noise in the measured AE spectra consists of basically all the frequencies (Figure 9). The plot of the power spectral density (Figure 13) is close enough to ideal white noise (in which case it would be completely flat). The claim that the noise in the measured AE spectra is close to ideal white noise is further supported by the shape of the autocorrelation function presented in Figure 15, where only one strong peak at 0 shift is observed. From the signalprocessing point of view it is not important to what sub-class (i.e., Shot) of white noise it actually belongs. The consequence of white noise is that it cannot be successfully filtered out by any signal-processing spectral method.

3. Is the noise temperature dependent? According to the results presented in Figure 19, the conclusion is reached that for the conditions in which the experiments were carried out in this case, as the temperature of the sample increases from $200{ }^{\circ} \mathrm{C}$ to $800{ }^{\circ} \mathrm{C}$ no significant change in the noise level of the $\mathrm{AE}$ spectra can be observed. Therefore, as far as the noise is concerned, the same procedures for the automatic treatment of the AE spectra can be used for these cases as well.

S1. Can the noise produced by the AE spectra simulator be compared to the measured noise? The conclusion is reached that the noise produced by the AE spectra simulator can be compared to the noise in the measured AE spectra (Figures 13 to 16). It is obvious that the noise amplitude level does not change with the AE kinetic energy and that the plot of the power spectral density is close to that of ideal white noise also for the noise from the simulated $\mathrm{AE}$ spectra.

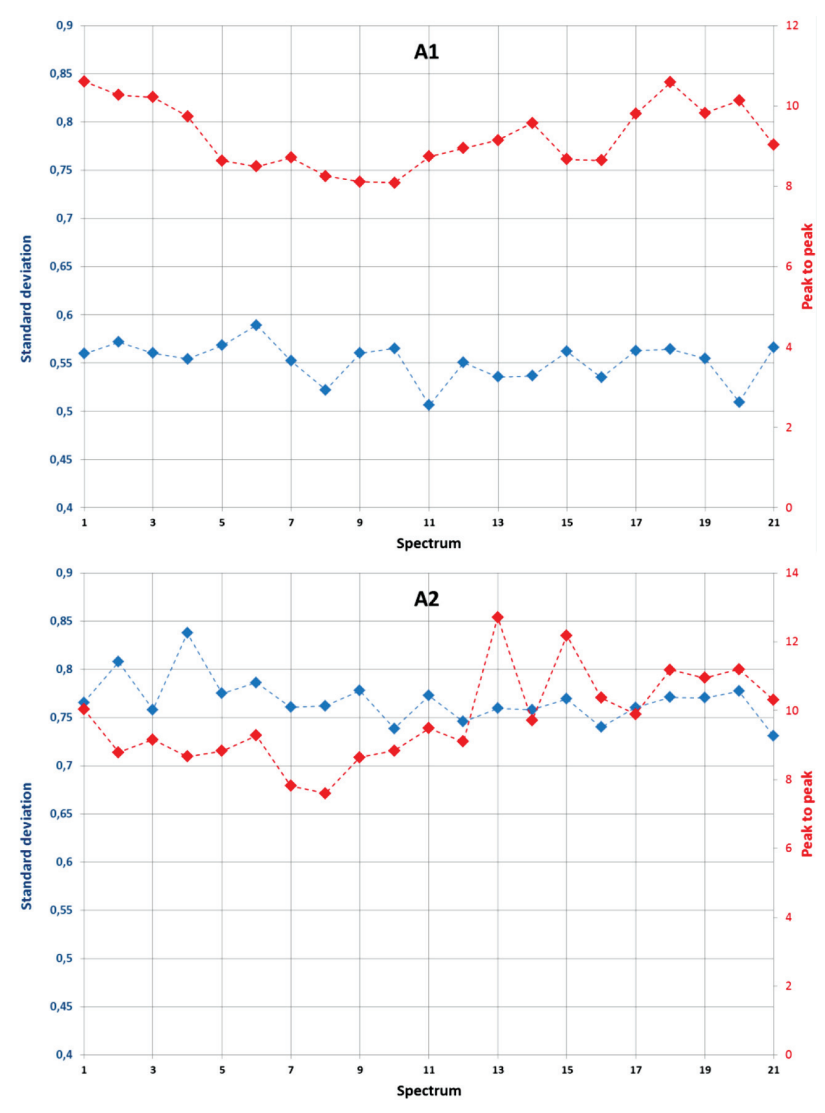

Figure 19: Noise represented as the peak-to-peak difference and as the standard deviation for the 21 Auger electron spectra measured at point A1 and for the 21 spectra measured at point A2 
S2. What are the differences between the measured and simulated noise? Comparing Figure 13 and Figure 16 it is evident that the plot of the power spectral density of the simulated noise comes slightly closer to that of ideal white noise compared to the noise from the measured AE spectra. This is a direct consequence of the more uniform amplitude distribution of the simulated noise compared to the measured one, as shown in Figure 17.

S3. Can the simulated noise adequately represent the measured noise or should the AE spectra simulator be appropriately tuned in order to give a better representation of the measured noise? Based on the answers to questions S1 and S2, it can be concluded that the simulated noise does adequately represent the measured noise. The fact that the simulated noise shows some properties that come slightly closer to the ideal white noise compared to the measured one only serves better the intended purpose of using simulated spectra for testing the noise-reduction routines. This means that the simulated noise, being more similar to white noise, is slightly harder to remove than the measured noise; therefore, whatever routine is developed that will be successful in removing the simulated noise, will remove the measured noise with even greater efficiency. Therefore, no corrections are needed for the AE spectra simulator in this regard.

The findings of the described research work on the properties of AE spectral noise suggest a method for its extraction.

\section{Acknowledgement}

Authors would like to acknowledge the financial support provided by ARRS, The Slovenian Research Agency, through the project groups P2-0132 Surface Physics and Chemistry of Metallic Materials, and P2-0056 Vacuum technique and materials for electronics.

\section{REFERENCES}

${ }^{1}$ Y. E. Strausser, Auger Electron Spectroscopy, in: C. A. Evans Jr., S Wilson, C. R. Brundle (Eds.), Encyclopedia of Materials Characterization, Butterworth-Heinemann, Stoneham, Massachusetts, 1992, 310-323

${ }^{2}$ J. T. Grant, AES: Basic Principles, Spectral Features and Qualitative Analysis, in J. T. Grant, D. Briggs (Eds.), Surface Analysis by Auger and X-ray Photoelectron Spectroscopy, IM Publications, Chichester, 2003, 57-87

${ }^{3}$ Microlab 310-F-Operator's Manual, VG Scientific, 1997

${ }^{4}$ L. C. Chao, S.H. Yang, Growth and Auger electron spectroscopy characterization of donut-shaped $\mathrm{ZnO}$ nanostructures, Appl. Surf. Sci. 253 (2007) 17, 7162-7165, doi:10.1016/j.apsusc.2007.02.184

${ }^{5}$ R. Yousefi, B. Kamaluddin, M. Ghoranneviss, F. Hajakbari, Auger and photoluminescence analysis of $\mathrm{ZnO}$ nanowires grown on AlN thin film. App. Surf. Sci. 255 (2009) 15, 6985-6988, doi:10.1016/ j.apsusc.2009.03.025
${ }^{6}$ J. Liu, G. G. Hembree, G. E. Spinnler, J. A. Venables, Nanometerresolution surface analysis with Auger electrons, Ultramicroscopy 52 (1993) 3-4, 369-376, doi:10.1016/0304-3991(93)90048-3

${ }^{7}$ C. Vollmer, P. Hoppe, F. J. Stadermann, C. Floss, F. E. Brenker, NanoSIMS analysis and Auger electron spectroscopy of silicate and oxide stardust from the carbonaceous chondrite Acfer 094. Geochimica et Cosmochimica Acta 73 (2009) 23, 7127-7149, doi:10.1016/j.gca.2009.08.015

${ }^{8}$ G. G. Hembree, J. A. Venables, Nanometer-resolution scanning Auger electron microscopy, Ultramicroscopy 47 (1992) 1-3, 109-120, doi:10.1016/0304-3991(92)90188-P

${ }^{9}$ F. Tang, L. Yu, X. Huang, J. Guo, Characterization of adsorption and distribution of polyelectrolyte on stability of nano-zirconia suspensions by auger electron spectroscopy, Nanostr. Mater. 11 (1999) 4, 441-450, doi:10.1016/S0965-9773(99)00325-6

${ }^{10}$ B. Poniku, I. Belič, M. Jenko, The Modeling of Auger Spectra, Mater. and Technol. 45 (2011), 39-46

${ }^{11}$ M. P. Seah, C. P. Hunt, Auger electron spectroscopy: Method for the accurate measurement of signal and noise and a figure of merit for the performance of AES instrument sensitivity, Rev. of Sci. Instrum. 59 (1988) 2, 217-227, doi:10.1063/1.1140230

${ }^{12}$ D. T. L. van Agterveld, S.A. Koch, G. Palasantzas, J. T. M. De Hosson, Ultra high vacuum scanning Auger/electron microscopy studies of oxidation and B surface segregation of in situ fractured B-doped Ni3Al alloys, Surf. Sci. 482-485 (2001) 1, 254-259. doi:10.1016/S0039-6028(01)00910-4

${ }^{13}$ F. Christien, Y. Borjon-Piron, R. Le Gall, S. Saillet, Quantifying the effect of fracture surface topography on the scattering of grain boundary segregation measurement by Auger electron spectroscopy, Mater. Charact. 61 (2010) 1, 73-84, doi:10.1016/j.matchar.2009.10. 010

${ }^{14} \mathrm{~S}$. Belkhiat, F. Keraghel, Segregation study of the phase on the Al-Li alloy surface using Auger electron Spectroscopy, Phys. Procedia, 2 (2009) 3, 1343-1349

${ }^{15}$ P. Gopalan, R. Rajaraman, G. Amarendra, Surface co-segregation of minor alloying elements in Ti-modified stainless steel studied by Auger electron spectroscopy, J. of Nuclear Mater. 349 (2006) 1-2, 78-181, doi:10.1016/j.jnucmat.2005.10.010

${ }^{16}$ P. Lejček, J. Pokluda, P. Šandera, J. Horníková, M. Jenko, Solute segregation at $46.8^{\circ}(111)$ twist grain boundary of a phosphorus doped Fe-2.3\%V alloy, Surf. Sci. 606 (2012) 3-4, 258-262

${ }^{17}$ J. C. Vickerman, I. S. Gilmore (Eds.), Surface analysis-the principal Techniques, Wiley, Chichester, 2009, doi:10.1002/9780470721582

${ }^{18}$ M. Jenko, B. Erjavec, B. Praček, AES studies of surface phenomena on liquid indium solder, Vac. 40 (1990) 1-2, 77-79, doi:10.1016/ 0042-207X(90)90124-H

${ }^{19}$ M. Jenko, F. Vodopivec, B. Praček, Surface segregation of antimony in Fe-Si steel for grain oriented sheets, Appl. Surf. Sci. 70/71 (1993) 118-122, doi:10.1016/0169-4332(93)90410-D

${ }^{20}$ B. Poniku, I. Belič, M. Jenko, The Auger spectra recognition and modeling: Modeling Auger spectra for effective background removal and noise reduction, Lambert Academic Publishing, Saarbrücken, 2011, doi:10.13140/2.1.3620.7045

${ }^{21}$ M. Jenko, B. Erjavec, M. Milun, High-resolution AES analysis and imaging of In-80Sn oxidized surface using field emission auger microprobe, Vac. 71 (2003) 1-2, 9-25, doi:10.1016/S0042207X(02)00708-X

${ }^{22}$ C. D. Motchenbacher, J. A. Connelly, Low-noise electronic system design, Wiley Interscience, 1993

${ }^{23}$ A. O. Hakeem, Generalized free Gaussian white noise, International Journal of Advanced Mathematical Sciences, 4 (2016) 1, 18-20

${ }^{24}$ G. R. Arce, Nonlinear Signal Processing: A Statistical Approach, Wiley: New Jersey, USA, 2005, doi:10.1002/0471691852

${ }^{25}$ W. H. Press, B. P. Flannery, S. A. Teukolsky, W. T. Vetterling, Numerical recipies - The art of scientific computing, Cambridge University Press, GB, 1986 